\title{
JMSR
}

Journal of Medical

and Scientific Research

\section{The impact of ultrafiltration, diuretic therapy, heart failure and diabetes mellitus on sodium homeostasis in patients with ESRD: A cross-sectional analysis}

\author{
Madhura $\mathrm{AR}^{1, *}$ and Jayaraj $\mathbf{P M}^{2}$ \\ ${ }^{1}$ Department of General Medicine, Mother Hospital, Thrissur, Kerala, India \\ ${ }^{2}$ Department of Nephrology, Mother Hospital, Thrissur, Kerala, India
}

\begin{abstract}
Background: Sodium homeostasis is significantly altered in patients with End Stage Renal Disease (ESRD). Higher inter-dialytic weight gain, larger volume of ultrafiltration during hemodialysis, presence of heart failure and associated diabetes mellitus increase the risk of hyponatremia in these patients. Severity of hyponatremia can predict morbidity and mortality in ESRD.
\end{abstract}

Objectives: To study the impact of average weight gain, average ultrafiltrate removed per dialysis, associated heart failure and diabetes mellitus on serum sodium levels in ESRD patients.

Methods: We studied 60 patients of ESRD undergoing hemodialysis. History of co-morbidities, duration of hemodialysis, diuretic usage, dialysis records were obtained and their impact on serum sodium levels were analysed statistically.

Results: Among 60 participants, 18\% had mild, 38\% had moderate and 44\% had severe hyponatremia. The average inter-dialytic weight gain was $1.86 \pm 0.55 \mathrm{~L}$ in mild, $2.19 \pm 0.56 \mathrm{~L}$ in moderate and $2.80 \pm 0.44 \mathrm{~L}$ in severe hyponatremia groups $(\mathrm{p}=0.0001)$. The average ultrafiltration per hemodialysis was $1.69 \pm 0.56 \mathrm{~L}$ in mild, $2.02 \pm 0.53 \mathrm{~L}$ in moderate and $2.62 \pm 0.36 \mathrm{~L}$ in severe hyponatremia groups $(\mathrm{p}=0.0001) .53 \%$ patients were on furosemide out of whom $72 \%$ had severe hyponatremia $(\mathrm{p}=0.0001) .58 \%$ patients had chronic heart failure (CHF) out of whom $74 \%$ had severe hyponatremia ( $\mathrm{p}=0.0001$ ). $70 \%$ patients had diabetes mellitus (DM) out of whom $62 \%$ had severe hyponatremia $(\mathrm{p}=0.0001)$.

Conclusion: There was a significant negative correlation between average weight gain/average ultrafiltration per dialysis and serum sodium levels. The study strongly established the impact of heart failure and diabetes mellitus on serum sodium levels in ESRD.

Keywords: inter-dialytic weight gain; ultrafiltration; ESRD; heart failure; diabetes; sodium homeostasis

*Corresponding author: Dr Madhura A R, Senior Resident, Department of General Medicine, Mother Hospital, Thrissur, Kerala- 680012, India. Mobile: 9611847280; Email ID: madhura140@gmail.com

Received 4 August 2020; Revised 15 September 2020; Accepted 22 September 2020; Published 29 September 2020

Citation: Madhura AR, Jayaraj PM. The impact of ultrafiltration, diuretic therapy, heart failure and diabetes mellitus on sodium homeostasis in patients with ESRD: A cross-sectional analysis. J Med Sci Res. 2020; 8(4):160-165. DOI: http://dx.doi. org/10.17727/JMSR.2020/8-21

Copyright: (C) 2020 Madhura AR et al. Published by KIMS Foundation and Research Center. This is an open-access article distributed under the terms of the Creative Commons Attribution License, which permits unrestricted use, distribution, and reproduction in any medium, provided the original author and source are credited. 


\section{Introduction}

Serum sodium concentration in humans is tightly regulated, with normal levels between 135 and 144 $\mathrm{mEq} / \mathrm{L}$ [1]. The physiological regulation of serum sodium level is maintained by balancing water intake and water excretion; the former through control of thirst sensation and the latter through control of arginine vasopressin (AVP) secretion. In End Stage Renal Disease (ESRD), the kidneys lose the ability to concentrate urine in response to circulating AVP which can cause an imbalance between water retention and excretion and leads to hyponatremia [2].

ESRD patients can have dilutional or depletional hyponatremia. Dilutional hyponatremia is a condition in which intravascular volume is increased and the total amount of sodium is not depleted. Therefore, inappropriate intravascular fluid retention leads to low serum sodium concentration. Ultrafiltration is a process of removing isotonic fluid without affecting effective circulating volume. Ultrafiltration can remove a higher amount of sodium in addition to isotonic fluid resulting in depletional hyponatremia. Also, if an isotonic fluid removal rate by ultrafiltration is too fast to refill intravascular sodium from extracellular interstitial space, there can be reduction of circulating volume and sodium depletion [3].

Diuretics are essential in treating fluid balance, blood pressure control, prevention of hyperkalemia and urine amount regulation in chronic kidney disease (CKD) population [4]. Overuse of diuretics causes both volume and sodium depletion through many mechanisms: (1) Stimulation of AVP release secondary to diuretic-induced volume contraction, (2) Decrease in GFR from intravascular volume contraction, (3) Inhibition of urinary dilution capacity due to interference with $\mathrm{Na}+$ absorption in the distal segments, and (4) Hypokalemia induced intracellular shift of $\mathrm{Na}+[5]$.

This causes further stimulation of the RAS due to increased distal $\mathrm{Na}+$ delivery thereby increasing angiotensin II, a well-known stimulant of arginine vasopressin (AVP) secretion. AVP is critical in initiating and exacerbating renal damage [6]. A sustained stimulation of vasopressin receptors induced intrarenal RAS activation, glomerular hyperfiltration, and hypertrophy, causes glomerulosclerosis and progressive renal injury. Volume depletion also decreases renal perfusion and increases the susceptibility to analgesics and nephrotoxic agents [7].

In chronic heart failure (CHF), progressive decrease in cardiac output leads to a continued release of AVP despite a reduction in osmolality, thus leading to hyponatremia. It is likely that presence of hyponatremia reflects a greater activation of the renin-angiotensin-aldosterone system (RAAS) and sympathetic nervous system leading to increased mortality, especially in ESRD [8].

Diabetes mellitus (DM) per se is associated with hyponatremia, independently of the presence of hyperglycemia [10]. It has been suggested that the altered vasopressin regulation in diabetes mellitus, the increased insulin induced potentiation of vasopressin-induced aquaporin AQP2 water channels expression and the absorption of water from the gastrointestinal (GI) tract due to slower stomach emptying may play a role in the association between DM and decreased serum sodium levels $[11,12]$.

Our objective is to assess the impact of ultrafiltration during hemodialysis, diuretic usage, presence of CHF and presence of DM on serum sodium levels of ESRD patients and to study the association between serum sodium and these factors.

\section{Material and methods}

This was a cross-sectional observational study conducted on 60 patients with ESRD undergoing maintenance hemodialysis thrice a week. Based on the previously conducted studies and the clinical experience of our team, convenient sampling method was applied. Informed consent was taken from all the participants. Study participants were older than 18 years diagnosed to have ESRD of varied etiology undergoing maintenance HD thrice weekly in our dialysis unit. Patients who were taking ADH antagonist drugs like Tolvaptan and those with underlying decompensated cirrhosis were excluded from the study. Clinical history of co-morbidities, duration of hemodialysis and diuretic usage was obtained. Complete hemogram, ESR, CRP, RFT, LFT, serum electrolyte panel and urine microscopy were done for all patients. Inter-dialytic weight gain and 
ultrafiltrate removed per session of dialysis was tabulated. Patients were divided into 3 categories based on severity of hyponatremia: Mild (130-135 $\mathrm{mEq} / \mathrm{L})$, moderate $(125-129 \mathrm{mEq} / \mathrm{L})$ and severe $(<125 \mathrm{mEq} / \mathrm{L})$.

The study data was analysed using the statistical software SPSS version 23. Results on continuous measurements are presented in mean \pm SD (minmax) and results on categorical measurements are presented in number (\%). Significance is assessed at $5 \%$ level of significance. $P$-value $<0.05$ is taken as significant. Chi-square test, Pearson correlation coefficient, unpaired $t$ test, ANOVA and post hoc ANOVA, linear regression analysis are carried out wherever found appropriate. Classification of correlation coefficient (r): 0.1-0.3 = small correlation, 0.3-0.5 = moderate correlation, $0.5-0.7=$ large correlation, 0.7 $0.9=$ very large correlation, $0.9-1.0=$ nearly perfect correlation and $1=$ perfect correlation. Significant figures: $p$-value $\leq 0.01=$ strongly significant, 0.01 $0.05=$ moderately significant and $0.05-0.10=$ suggestive significance.

\section{Results}

60 patients of ESRD undergoing maintenance hemodialysis were studied. Among the study population, 60\% (n=36) were males and $40 \%$ $(\mathrm{n}=24)$ were females. $45 \%(\mathrm{n}=27)$ were smokers and $35 \%(n=21)$ were alcoholics, $70 \%(n=42)$ had diabetes and all 100\% ( $\mathrm{n}=60)$ had hypertension. Among 60 participants, 18\% ( $\mathrm{n}=11$ ) had mild (130$135 \mathrm{mEq} / \mathrm{L}), 38 \%(\mathrm{n}=23)$ had moderate $(125-129$ $\mathrm{mEq} / \mathrm{L})$ and $44 \%(\mathrm{n}=26)$ had severe $(<125 \mathrm{mEq} / \mathrm{L})$ hyponatremia. The average inter-dialytic weight gain was $1.86 \pm 0.55 \mathrm{~L}$ in the patients who had mild hyponatremia, $2.19 \pm 0.56 \mathrm{~L}$ in those with moderate and $2.80 \pm 0.44 \mathrm{~L}$ in those with severe hyponatremia. There was a significant negative correlation between serum sodium and average weight gain $(\mathrm{r}=-0.506, \mathrm{p}=0.0001)$. The average ultrafiltrate removed per hemodialysis session was $1.69 \pm 0.56$ $\mathrm{L}$ in mild, $2.02 \pm 0.53 \mathrm{~L}$ in moderate and $2.62 \pm 0.36$ $\mathrm{L}$ in severe hyponatremia. There was a significant negative correlation between serum sodium and average ultrafiltrate removed per session ( $\mathrm{r}=-0.550$, $\mathrm{p}=0.0001$ ) (Table 1).

Table 1: Association between serum sodium and ultrafiltration

\begin{tabular}{|lccccc|}
\hline & Hyponatremia & Number & Mean & Std. Deviation & $p$-value ANOVA \\
\hline Average weight gain per & Severe & 26 & 2.8038 & 0.44157 & 0.0001 \\
dialysis & Moderate & 23 & 2.1870 & 0.56493 & 0.55354 \\
& Mild & 11 & 1.8591 & 0.63058 \\
Average UF per dialysis & Total & 60 & 2.3942 & 0.35644 & 0.0001 \\
& Severe & 26 & 2.6250 & 0.52825 & 0.55759 \\
& Moderate & 23 & 2.0217 & 1.6909 & 0.59192 \\
\hline
\end{tabular}

Among 60 patients, $53 \%(\mathrm{n}=32)$ were on furosemide out of whom $28 \%(n=9)$ had moderate and $72 \%$ $(n=23)$ had severe hyponatremia. $47 \%$ patients $(n=28)$ were on thiazides out of whom $39 \%(n=11)$ had mild, 50\% ( $\mathrm{n}=14)$ had moderate and $11 \%$ $(n=3)$ had severe hyponatremia. There was a strong association between hyponatremia and diuretic usage (both furosemide and thiazide: $\mathrm{p}=0.0001$ ) (Table 2).

All patients were on RAS blockers, out of whom $18 \%(\mathrm{n}=11)$ had mild, 38\% $(\mathrm{n}=23)$ had moderate and $44 \%(\mathrm{n}=26)$ had severe hyponatremia. $73 \%$ patients $(n=44)$ were on beta blockers, among who
7\% ( $\mathrm{n}=3)$ had mild, 34\% ( $=15)$ had moderate and $59 \%(n=26)$ had severe hyponatremia. $98 \%$ of patients $(n=59)$ were on calcium channel blockers, out of whom 17\% ( $n=10)$ had mild, 39\% ( $n=23)$ had moderate and $44 \%(n=26)$ had severe hyponatremia $(\mathrm{p}=0.176) .58 \%$ patients $(\mathrm{n}=25)$ had CHF out of whom $26 \%(n=9)$ had moderate and $74 \%(n=26)$ had severe hyponatremia. The mean serum sodium among patients with CHF was $123.54 \pm 2.28 \mathrm{mEq} / \mathrm{L}$ and among those without CHF was $129.44 \pm 2.00$ $\mathrm{mEq} / \mathrm{L}$. There was a strong association between hyponatremia and presence of CHF $(p=0.0001)$ (Table 3). 
Table 2: Association between serum sodium and diuretic usage.

\begin{tabular}{|lcccc|}
\hline Hyponatremia & \multicolumn{2}{c}{ Furosemide } & Total & $\begin{array}{c}\text { p-value } \\
\text { (Chi-square test) }\end{array}$ \\
\cline { 2 - 5 } Severe & No & Yes & 26 & 0.0001 \\
Moderate & 3 & 23 & 23 & 11 \\
Mild & 14 & 9 & 60 & \\
Total & 11 & 0 & & Total \\
Thiazide & 28 & 32 & 26 & 0.0001 \\
Hyponatremia & & & 23 \\
Severe & No & Yes & 11 \\
Moderate & 23 & 3 & 60 \\
Mild & 9 & 14 & 11 & \\
Total & 0 & 28 & & \\
\hline
\end{tabular}

Table 3: Association between serum sodium and chronic heart failure.

\begin{tabular}{|lcccc|}
\hline \multirow{2}{*}{ Hyponatremia } & \multicolumn{2}{c}{ Chronic heartfailure } & Total & $\begin{array}{c}\text { p-value } \\
\text { (Chi-square test) }\end{array}$ \\
\cline { 2 - 5 } Severe & No & Yes & 26 & 0.0001 \\
Moderate & 0 & 26 & 23 & 11 \\
Mild & 14 & 9 & 60 & \\
Total & 11 & 0 & 35 & \\
\hline
\end{tabular}

Among the study population, $70 \%(n=42)$ had DM out of whom $7 \%(n=3)$ had mild, $31 \%(n=13)$ had moderate and $62 \%(n=26)$ had severe hyponatremia. The mean serum sodium among patients with DM was $124.48 \pm 2.47 \mathrm{mEq} / \mathrm{L}$ and among those without DM was $129.55 \pm 2.09 \mathrm{mEq} / \mathrm{L}$. There was a significant association between hyponatremia and presence of DM ( $r=-0.706, p=0.0001)$ (Table 4).

Table 4: Association between serum sodium and diabetes mellitus.

\begin{tabular}{|lcccc|}
\hline Hyponatremia & \multicolumn{2}{c}{ DM } & Total & $\begin{array}{c}p \text {-value } \\
\text { (Chi-square test) }\end{array}$ \\
\cline { 2 - 5 } Severe & No & Yes & 26 & 0.0001 \\
Moderate & 0 & 26 & 23 & 11 \\
Mild & 10 & 13 & 60 & \\
Total & 8 & 3 & 42 & \\
\hline
\end{tabular}

\section{Discussion}

We conducted a cross-sectional study of 60 ESRD patients undergoing maintenance hemodialysis and observed the association of serum sodium with ultrafiltration, diuretic usage, CHF and DM. The patients who had higher inter-dialytic weight gain and those with larger volume of ultrafiltrate removed per dialysis had much lower serum sodium levels suggesting a significant association between the two variables ( $\mathrm{p}=0.0001)$. Out of 60 patients, $53 \%$ were on loop diuretics and $47 \%$ on thiazide group of drugs. There was a strong association between hyponatremia and use of diuretics ( $\mathrm{p}=0.0001) .58 \%$ of ESRD patients had associated CHF out of whom $74 \%$ had severe hyponatremia with a mean of $123.54 \pm 2.28 \mathrm{mEq} / \mathrm{L}$, suggesting a strong association 
( $p=0.0001$ ). $70 \%$ of the study population were diabetic out of whom $62 \%$ had severe hyponatremia establishing a strong association $(0=0.0001)$.

Kitai et al [3] studied 188 patients who were enrolled in the cardiorenal rescue study in acute decompensated heart failure (CARRESS) trial. Study included all patients who were hospitalized with HF, irrespective of LVEF, who had renal dysfunction and persistent signs of congestion. The incidence of hyponatremia was significantly higher in the ultrafiltration group than those receiving conventional treatment $(p=0.002)$. Lim et al [4] investigated whether hyponatremia is associated with fluid status and is a prognostic indicator for adverse outcomes in a CKD cohort of 4,766 patients with 1,009 diuretic users. The diuretic users showed higher percentage of CHF (27.7\%), DM (65.5\%) and significantly lower sodium levels $(\mathrm{p}<0.001)$ than non-diuretic users. $85 \%$ of patients on diuretics with DM had serum sodium $<141 \mathrm{mEq} / \mathrm{L}$ whereas $15 \%$ of them had $>141 \mathrm{mEq} / \mathrm{L}$. $84 \%$ of patients on diuretics with CHF had serum sodium $<141 \mathrm{mEq} / \mathrm{L}$ whereas $16 \%$ of them had $>141 \mathrm{mEq} / \mathrm{L}$. This study showed that hyponatremia was associated with excessive volume and volume depletion, in diuretic users, but not in diuretic non-users. Baek et al [13] retrospectively analysed 90-day and 1-year all-cause mortality in 599 hemodialysis patients in relation to pre-dialysis serum sodium. $67.9 \%$ patients were diabetic and $12.2 \%$ had CHF, $79.8 \%$ were on loop diuretics and $33 \%$ were on thiazides. The study established the relationship between severe hyponatremia and 90-day /1-year mortality rate (90day mortality: $\mathrm{HR}=2.367, \mathrm{p}=0.037$, 1-year mortality: $\mathrm{HR}=1.802, \mathrm{p}=0.040$ ). Pliquett et al [14] studied 262 patients with cardiorenal syndrome out of whom $34.4 \%$ of patients presented with Hyponatremia. Hypovolemia was more frequently encountered in hyponatremic than in non-hyponatremic CRS patients. The number of prescribed diuretic drug classes and, the dosages of hydrochlorothiazide $(p=0.002)$ and furosemide $(p=0.003)$ were the possible underlying reasons. The in-hospital mortality was higher among hyponatremic (15.6\%) than among non-hyponatremic (7.6\%) patients. The study showed that hyponatremic patients were more likely to have hypovolemia, and had a higher likelihood for compromised renal status. Sahin et al [15] investigated the association of low serum sodium levels in relation to glycemic control in hemodialysis (HD) patients. In adjusted Cox regression analysis, lowest sodium quartile was associated with 2.13fold increased risk of overall mortality $(\mathrm{p}<0.001)$. The predictivity of low serum sodium was prominent in diabetic subjects but not in nondiabetics. Waikar et al [16] studied 1549 oligoanuric participants in the HEMO study, a randomized controlled trial of hemodialysis patients, and examined the effect of hemodialysis dose and flux. Lower predialysis serum sodium concentration was associated with an increased risk of death. They concluded that hyponatremia itself could be a causal determinant of mortality in the broader population.

Our study results are comparable to many other studies which established similar association.

Higher inter-dialytic weight gain, larger ultrafiltrate volume removed during hemodialysis sessions, overuse of diuretic therapy, presence of CHF and Diabetes mellitus increase the risk of hyponatremia among ESRD patients. The severity of hyponatremia is directly proportional to the morbidity and mortality in ESRD patients. Appropriate correction as and when required maintains the fluid and electrolyte balance which can significantly reduce the long-term adverse effects and improve the quality of life of such patients.

\section{Conclusion}

Ultrafiltration, diuretic therapy, presence of heart failure and diabetes mellitus have a major impact in causing hyponatremia in ESRD patients undergoing hemodialysis. Serum sodium serves as a risk marker for morbidity and mortality in such patients.

\section{Conflicts of interest}

Authors declare no conflicts of interest.

\section{References}

[1] Kasper DL, Fauci AS, Hauser SL, Longo DL, Jameson JL, et al. Harrison's principles of Internal Medicine. 20th ed. New York, McGraw-Hill, 2018.

[2] Kovesdy CP. Significance of hypo- and hypernatremia in chronic kidney disease. Nephrol Dial Transplant. 2012; 27(3):891-898.

[3] Kitai T, Grodin JL, Kim YH, Tang WH. Impact of Ultrafiltration on Serum Sodium Homeostasis and its Clinical Implication in Patients with Acute Heart Failure, Congestion, and Worsening Renal Function. Circ Heart Fail. 2017; 10(2):e003603. 
[4] Lim LM, Tsai NC, Lin MY, Hwang DY, Lin HY, et al. hyponatremia is associated with fluid imbalance and adverse renal outcome in chronic kidney disease patients treated with diuretics. Sci Rep. 2016; 6:36817.

[5] Romanovsky A, Bagshaw S, Rosner MH. Hyponatremia and congestive heart failure: a marker of increased mortality and a target for therapy. Int J Nephrol. 2011; 2011:732746.

[6] Bolignano D, Zoccali C. Vasopressin beyond water: implications for renal diseases. Curr Opin Nephrol Hypertens. 2010; 19(5):499-504.

[7] Arampatzis S, Funk GC, Leichtle AB, Fiedler GM, Schwarz $\mathrm{C}$, et al. Impact of diuretic therapy-associated electrolyte disorders present on admission to the emergency department: a cross-sectional analysis. BMC Med. 2013; 11:83.

[8] Rosner MH, Ronco C. Hyponatremia in heart failure: the role of arginine vasopressin and its antagonism. Congest Heart Fail. 2010; 16(Supp. 1):S7-14.

[9] Liamis G, Rodenburg EM, Hofman A, Zietse R, Stricker BH, et al. Electrolyte disorders in community subjects: prevalence and risk factors. Am J Med. 2013; 126(3):256-263.

[10] Liamis G, Tsimihodimos V, Elisaf M. Hyponatremia in diabetes mellitus: clues to diagnosis and treatment. J Diabetes Metab. 2015; 6(6):1-3.

[11] Bankir L, Bardoux P, Ahloulay M. Vasopressin and diabetes mellitus. Nephron. 2001; 87(1):8-18.

[12] Bustamante M, Hasler U, Kotova O, Chibalin AV, Mordasini $\mathrm{D}$, et al. Insulin potentiates AVP-induced AQP2 expression in cultured renal collecting duct principal cells. Am J Physiol Renal Physiol. 2005; 288(2):F334-F344.

[13] Baek SH, Kim S, Na KY, Kim S, Chin HJ. Predialysis hyponatremia and mortality in elderly patients beginning to undergo hemodialysis. Korean J Intern Med. 2018; 33(5):970-979

[14] Pliquett RU, Schlump K, Wienke A, Bartling B, Noutsias M, et al. Diabetes prevalence and outcomes in hospitalized cardiorenal-syndrome patients with and without hyponatremia. BMC Nephrol. 2020; 21(1):393.

[15] Sahin OZ, Asci G, Kircelli F, Yilmaz M, Duman S, et al. The impact of low serum sodium level on mortality depends on glycemic control. Eur J Clin Invest. 2012; 42(5):534-540.

[16] Waikar SS, Curhan GC, Brunelli SM. Mortality associated with low serum sodium concentration in maintenance hemodialysis. Am J Med. 2011; 124(1):77-84.

[17] Canaud B, Kooman J, Selby NM, Taal M, Francis S, et al. Sodium and water handling during hemodialysis: new pathophysiologic insights and management approaches for improving outcomes in end-stage kidney disease. Kidney Int. 2019; 95(2):296-309.

[18] Rhee CM, Ravel VA, Ayus JC, Sim JJ, Streja E, et al. Predialysis serum sodium and mortality in a national incident hemodialysis cohort. Nephrol Dial Transplant. 2016; 31(6):992-100.

[19] Dekker MJ, Marcelli D, Canaud B, Konings CJAM, Leunissen KM, et al. Unraveling the relationship between mortality, hyponatremia, inflammation and malnutrition in hemodialysis patients: results from the international MONDO initiative. Eur J Clin Nutr. 2016; 70(7):779-784.

[20] Hecking M, Karaboyas A, Saran R, Sen A, Hörl WH, et al. Predialysis serum sodium level, dialysate sodium, and mortality in maintenance hemodialysis patients: the Dialysis Outcomes and Practice Patterns Study (DOPPS). Am J Kidney Dis. 2012; 59(2):238-248.
[21] Hoorn EJ, Zietse R: Hyponatremia and mortality: moving beyond associations. Am J Kidney Dis. 2013; 62(1):139149.

[22] Eknoyan G, Beck GJ, Cheung AK, Daugirdas JT, Greene T, et al. Effect of dialysis dose and membrane flux in maintenance hemodialysis. N Engl J Med. 2002; 347(25):2010-2019. 